\title{
An Atypical Presentation of Fulminant Myocarditis Secondary to COVID-19 Infection
}

\author{
Ivan Richard ${ }^{1}$, Bracha Robinson ${ }^{1}$, Amanda Dawson ${ }^{1}$, Ashley Aya ${ }^{1}$, Rana Ali ${ }^{1}$ \\ 1. Internal Medicine, Hackensack Meridian Ocean Medical Center, Brick, USA
}

Corresponding author: Ivan Richard, ivan.richard@hackensackmeridian.org

\begin{abstract}
The potential etiologies of fulminant myocarditis include autoimmune diseases, infections, drug hypersensitivity, and drug/toxin reactions. We present an atypical case of fulminant myocarditis in a patient with a history of diabetic ketoacidosis with recent novel coronavirus (COVID-19) infection, who presented with acute upper gastrointestinal bleeding. The patient improved with a three-day course of methylprednisolone 1 gram daily.
\end{abstract}

Categories: Cardiology, Internal Medicine, Infectious Disease

Keywords: fulminant myocarditis, covid 19

\section{Introduction}

When a young adult with a history of type 1 diabetes mellitus and multiple episodes of diabetic ketoacidosis (DKA) presents with a suspected acute upper gastrointestinal bleed and a confirmed infection with coronavirus (COVID-19), the potential complications are numerous. While fever and cough have been found to be the most common symptoms, it is theorized that cardiac pathology is a late manifestation of COVID19 infection $[1,2]$. The theory explains that cardiac manifestations are a result of the virus propagating in and circulating from the respiratory tract to various other organ systems through the blood or lymphatic system or myocardial injury from an intense systemic inflammatory response [2]. We present this case to raise awareness about fulminant myocarditis as a complication of COVID-19, as well as its possible atypical presentations. We also hope to shine a spotlight on the need for future studies to determine whether the main cause of damage to the heart in fulminant myocarditis is COVID-19, as well as its most effective treatment.

\section{Case Presentation}

The patient is a 28 -year-old Caucasian woman with a history of diabetes mellitus type 1, diabetic gastroparesis, asthma, anxiety, depression with multiple previous episodes of DKA, and recent COVID-19 infection who was brought to the emergency department after she was found to be lethargic and covered in coffee ground emesis at home. Although she denied smoking, alcohol, and substance use, her medical records did have a questionable history of IV drug use. On physical examination, her vital signs were as follows: blood pressure of 70/38 mmHg, pulse rate of $144 \mathrm{bpm}$, respiratory rate of $30 \mathrm{rpm}$, and peripheral

Received 06/07/2020 Review began $06 / 25 / 2020$ Review ended 07/06/2020 Published 07/14/2020

(c) Copyright 2020

Richard et al. This is an open access article distributed under the terms of the Creative Commons Attribution License CC-BY 4.0., which permits unrestricted use, distribution, and reproduction in any medium, provided the original author and source are credited. capillary oxygen saturation $\left(\mathrm{SpO}^{2}\right)$ of $90 \%$ on 15 liters of a nonrebreather mask, and she was afebrile. She was in acute respiratory distress, tachypneic, and lethargic. Breath sounds were clear to auscultation bilaterally. Heart sounds were tachycardic, with a regular rhythm, and no appreciable murmurs. Her abdomen was nondistended, soft, nontender, with a nonpalpable liver and spleen. The patient had no peripheral edema in the extremities, which were cool to touch with $1+$ peripheral pulses bilaterally. There were no focal neurological deficits found on the physical examination.

Abnormal results of initial laboratory tests were as follows: white blood cell of $29 \times 10^{3} / \mathrm{uL}$ (reference range: $4.5-11 \times 10^{3} / \mathrm{uL}$ ) hemoglobin of $10.3 \mathrm{~g} / \mathrm{dL}$ (reference range: $12-16 \mathrm{~g} / \mathrm{dL}$ ), hematocrit of $31 \%$ (reference range: $35.0 \%-48.0 \%$ ), creatinine of $4.4 \mathrm{mg} / \mathrm{dL}$ (reference range: $0.44-1.00 \mathrm{mg} / \mathrm{dL}$ ), glucose of 1,679 mg/dL (reference range: $70-99 \mathrm{mg} / \mathrm{dL}$ ), anion gap of $46 \mathrm{mmol} / \mathrm{L}$ (reference range: $5-13 \mathrm{mmol} / \mathrm{L}$ ), carbon dioxide of $6 \mathrm{mmol} / \mathrm{L}$ (reference range: $24-31 \mathrm{mmol} / \mathrm{L}$ ), potassium of $2.9 \mathrm{mmol} / \mathrm{L}$ (reference range: $3.5-5.2 \mathrm{mmol} / \mathrm{L}$ ), lactic acid level of $17.1 \mathrm{mg} / \mathrm{dL}$ (reference range: $0.5-2 \mathrm{mmol} / \mathrm{L}$ ), C-reactive protein (CRP) of $2.47 \mathrm{mg} / \mathrm{dL}$ (reference range: 0.0-0.74 mg/dL), lactate dehydrogenase (LDH) of $296 \mathrm{U} / \mathrm{L}$ (reference range: $91-200 \mathrm{U} / \mathrm{L}$ ), ferritin of $119 \mathrm{ng} / \mathrm{mL}$ (reference range: $11-307 \mathrm{ng} / \mathrm{mL}$ ), and troponin of $0.04 \mathrm{ng} / \mathrm{mL}$ (reference range: $<0.04 \mathrm{ng} / \mathrm{mL}$ ). Arterial gas analysis post-intubation showed a $\mathrm{pH}$ of 7.17 (reference range: 7.35-7.45), carbon dioxide partial pressure of $12.9 \mathrm{mmHg}$ (reference range: $35-50 \mathrm{mmHg}$ ), and oxygen partial pressure of $317 \mathrm{mmHg}$ (reference range: $85-106 \mathrm{mmHg}$ ). Her urine toxicology screen was negative. The patient's electrocardiogram (ECG) showed a wide complex tachycardia with a heart rate of $119 \mathrm{bpm}$ and accelerated junctional rhythm. EKG was also significant for ST segment depression in the lateral leads and ST elevation in leads I and aVL, showing sinus tachycardia at $119 \mathrm{bpm}$ with low voltage and nonspecific ST changes in the lateral leads, and possible septal infarct (Figure 1). Her chest X-ray findings were suspicious for COVID-19. The patient was intubated for airway protection and hypoxic respiratory failure and was started on norepinephrine for the 


\section{Cureus}

maintenance of blood pressure. She was also started on an insulin drip for the management of DKA and broad-spectrum antibiotics coverage with IV vancomycin and piperacillin-tazobactam. The patient was then transferred to the intensive care unit and received IV potassium. Overnight the patient had an episode of ventricular tachycardia. An ECG at that time showed sinus rhythm with diffuse T-wave inversions and a new right bundle branch block. Her troponin I level eight hours after admission was $46 \mathrm{ng} / \mathrm{mL}$ (reference range: $<0.04 \mathrm{ng} / \mathrm{mL}$ ). An ECG performed at that time showed a sinus rhythm at $85 \mathrm{bpm}$ with nonspecific ST changes in the lateral leads and a possible septal infarct (Figure 2).
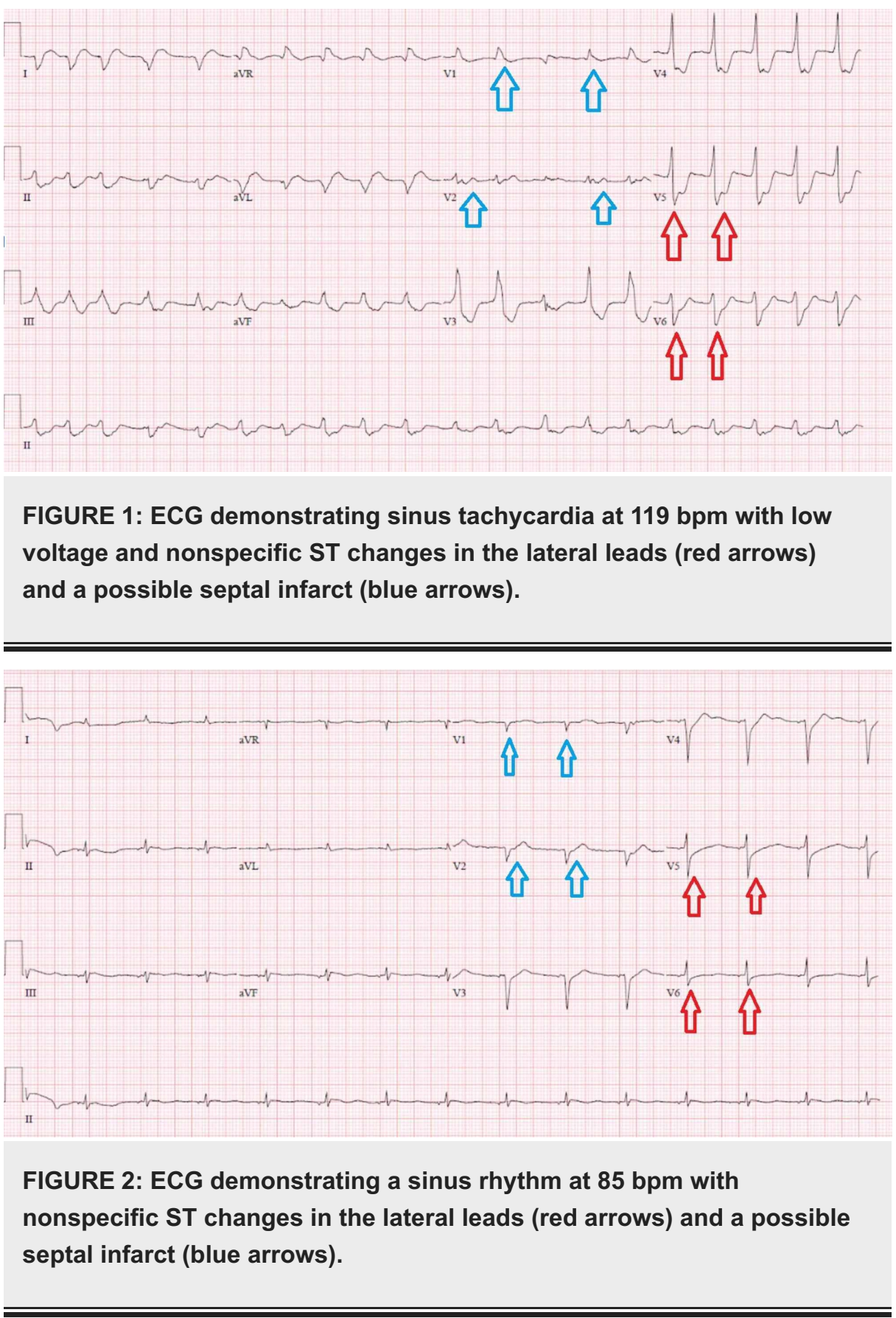

The cardiology service was consulted for non-ST segment elevation myocardial infarction, and they recommended both left and right heart catheterization with possible intervention. Prior to transferring the patient to the catheterization lab, a bedside echocardiogram was performed, which was significant for a left ventricular ejection fraction (LVEF) of $26-30 \%$ and mild mitral regurgitation. Once transferred, the patient's left and right heart catheterization found normal coronary arteries but elevated filling pressures and a reduced cardiac index of $1.9 \mathrm{~L} /$ minute $/ \mathrm{m}^{2}$ (reference range: $2.6-4.2 \mathrm{~L} /$ minute $/ \mathrm{m}^{2}$ ). At that time, cardiogenic shock secondary to fulminant myocarditis from COVID-19 was suspected. An Impella device (ABIOMED Inc., Danvers, MA) was placed in the left ventricle to assist in heart pumping. The patient was started on IV dobutamine and heparin drips, and norepinephrine was stopped. She underwent a cardiac MRI that showed myocardial necrosis, fibrosis, and hyperemia, indicating myocarditis according to the Lake Louise criteria 
(Figure 3). Her anion gap closed, her insulin drip was stopped, and COVID-19 testing was negative. The patient's hospital stay was complicated by acute oliguric renal failure, which improved with improvement in cardiac function. The patient's COVID myocarditis was treated with pulse dose IV methylprednisolone 1 gram daily for three days. The patient clinically improved with IV steroids. An echocardiogram performed three days later, showed an LVEF of $>55 \%$, without significant valvular disease. The Impella device was then removed, dobutamine was weaned off, and the patient was extubated the next day.

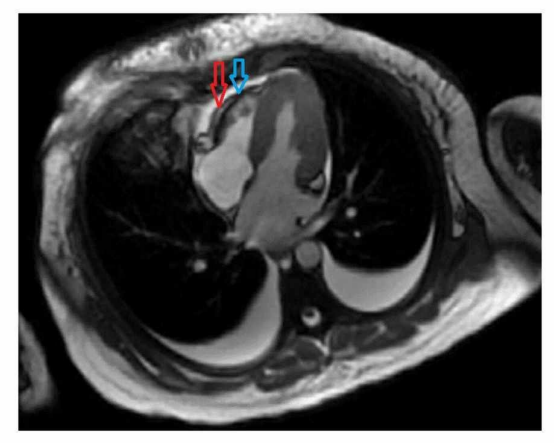

FIGURE 3: A four-chamber view of the patient's cardiac MRI with contrast enhancement, demonstrating subepicardial myocardial fibrosis and necrosis in the basal to mid-anteroseptal and anterior walls (red arrow). There is hyperemia and myocardial edema in the midanteroseptum (blue arrow).

\section{Discussion}

A COVID-19 study from China, published in 2020, found that the most common symptoms of viral infection were fever, cough, fatigue, and shortness of breath [1]. Inciardi et al. described cardiac pathology as a late manifestation of COVID-19 respiratory infection [2]. Cardiac manifestations of COVID-19 have been hypothesized to be the result of the virus propagating in and circulating from the respiratory tract to various other organ systems through the blood or lymphatic system or myocardial injury from an intense systemic inflammatory response [2]. The underlying inflammatory process associated with COVID-19 can present either with clear symptoms, as previously mentioned, or subclinically with the etiology found only on autopsy [3]. Among the different etiologies of myocarditis, viral infections are one of the most common causes of infectious causes [4]. In patients with a recent history of influenza-like syndrome, who subsequently present with chest pain, in addition to laboratory, ECG, and echocardiogram findings suggestive of acute coronary syndrome with a coronary angiogram negative for obstructive disease, focal myocarditis should be suspected [5]. According to Yang et al., inflammatory cells have been found in the alveoli of COVID patients, thus justifying the use of steroids [6]. Some sources have hypothesized that COVID binds to viral receptors on the cardiac myocytes, which leads to replication of the viral capsid proteins and the viral genome $[7,8]$.

Our patient was recently infected with COVID-19 and tested positive. She had a sudden onset of lethargy, gastrointestinal bleed, hemodynamic instability, renal insufficiency, hypoxemia, myocardial injury, and reduced myocardial contraction capability. All of the aforementioned are part of the diagnostic criteria for fulminant myocarditis [9]. The incidence of fulminant myocarditis appears to be low. Zeng et al. reported 419 COVID-19 cases, of which 32 had elevated troponin I, with only 2 of those patients found to have fulminant myocarditis [10]. That being said, other studies have confirmed the association between COVID infection and myocarditis [11]. According to Xu et al., heart tissue containing inflammatory infiltrates without viral inclusion bodies have been found in autopsies of COVID-19 patients [3]. Despite this, other studies have found that the viral load in COVID-19 patients is not the sole indicator of improvement in cardiac structure and function, leading to the suggestion that an immune response could be an important factor in myocarditis $[12,13]$. A potent immune response from hypoxia or viral infection of the myocytes could cause increased vascular permeability leading myocardial edema [14]. Tavazzi et al. found low-grade inflammation without myocyte necrosis in pathological studies of patients clinically diagnosed with severe 
myocarditis, suggesting that the effect on cardiac myocytes is either from a viremic phase or the transposition of infected alveolar macrophages [15]. Interestingly, they did not find cardiac myocytes with viral particles but did find non-specific changes, mainly focal myofibrillar lysis [15]. Other studies have found extrapulmonary distribution of COVID-19 RNA in the heart, kidneys, cerebrum, intestines, and lymph nodes $[16,17]$. Shakoory et al. promote the idea of specific anti-inflammatory treatments citing the survival benefit to patients in sepsis with hyper-inflammation who underwent trials of interleukin-1 antagonists [18]. No significant difference in mortality was reported in a 2013 Cochrane review of 8 randomized controlled trials that included 719 patients, observing the use of corticosteroids versus control groups for the treatment of viral myocarditis [19].

\section{Conclusions}

In our case of fulminant myocarditis, we attributed the patient's condition to viral infection with COVID-19 given her recent positive test prior to admission. We present this case to raise awareness of fulminant myocarditis as a complication of COVID-19, as well as its possible atypical presentations. A careful physical examination, diagnostic/laboratory testing, diagnostic cardiac intervention, and critical care management were crucial in this case. Future studies are needed to determine if the main cause of damage in fulminant myocarditis secondary to COVID-19 is due to direct viral infection or immunological mechanisms, as well as to assess the efficacy of the various anti-inflammatory treatments including corticosteroids, IV immunoglobulin, and interleukin-1 antagonists.

\section{Additional Information \\ Disclosures}

Human subjects: Consent was obtained by all participants in this study. Conflicts of interest: In compliance with the ICMJE uniform disclosure form, all authors declare the following: Payment/services info: All authors have declared that no financial support was received from any organization for the submitted work. Financial relationships: All authors have declared that they have no financial relationships at present or within the previous three years with any organizations that might have an interest in the submitted work. Other relationships: All authors have declared that there are no other relationships or activities that could appear to have influenced the submitted work.

\section{References}

1. Guan WJ, Ni ZY, Hu Y, et al.: Clinical characteristics of coronavirus disease 2019 in China . N Engl J Med. 2020, 382:1708-1720. 10.1056/NEJMoa2002032

2. Inciardi RM, Lupi L, Zaccone G, et al.: Cardiac involvement in a patient With coronavirus disease 2019 (COVID-19) [Online ahead of print]. JAMA Cardiol. 2020, 10.1001/jamacardio.2020.1096

3. Xu Z, Shi L, Wang Y, et al.: Pathological findings of COVID-19 associated with acute respiratory distress syndrome. Lancet Respir Med. 2020, 8:420-22. 10.1016/S2213-2600(20)30076-X

4. Fung G, Luo H, Qiu Y, Yang D, McManus B: Myocarditis. Circ Res. 2016, 118:496-514. 10.1161/CIRCRESAHA.115.306573

5. Esfandiarei M, McManus BM: Molecular biology and pathogenesis of viral myocarditis . Annu Rev Pathol. 2008, 3:127-155. 10.1146/annurev.pathmechdis.3.121806.151534

6. Yang X, Yu Y, Xu J, et al.: Clinical course and outcomes of critically ill patients with SARS-CoV-2 pneumonia in Wuhan, China: a single-centered, retrospective, observational study. Lancet Respir Med. 2020, 8:475-481. 10.1016/\$2213-2600(20)30079-5

7. Rahman JE, Helou EF, Gelzer-Bell R, et al.: Noninvasive diagnosis of biopsy-proven cardiac amyloidosis . J Am Coll Cardiol. 2004, 43:410-415. 10.1016/j.jacc.2003.08.043

8. Liu PP, Mason JW: Advances in the understanding of myocarditis . Circulation. 2001, 104:1076-1082. 10.1161/hc3401.095198

9. Wang D, Li S, Jiang J, et al.: Chinese Society of Cardiology expert consensus statement on the diagnosis and treatment of adult fulminant myocarditis. Sci China Life Sci. 2019, 62:187-202. 10.1007/s11427-018-9385-3

10. Zeng JH, Liu YX, Yuan J, et al.: First case of COVID-19 complicated with fulminant myocarditis: a case report and insights [Online ahead of print]. Infection. 2020, 10.1007/s15010-020-01424-5

11. Edwards S, Small JD, Geratz JD, Alexander LK, Baric RS: An experimental model for myocarditis and congestive heart failure after rabbit coronavirus infection. J Infect Dis. 1992, 165:134-140. 10.1093/infdis/165.1.134

12. Channappanavar R, Perlman S: Pathogenic human coronavirus infections: causes and consequences of cytokine storm and immunopathology. Semin Immunopathol. 2017, 39:529-539. 10.1007/s00281-017-0629$\mathrm{x}$

13. Huang KJ, Su IJ, Theron M, Wu YC, Lai SK, Liu CC, Lei HY: An interferon-gamma-related cytokine storm in SARS patients. J Med Virol. 2005, 75:185-194. 10.1002/jmv.20255

14. Wu J, Stefaniak J, Hafner C, et al.: Intermittent hypoxia causes inflammation and injury to human adult cardiac myocytes. Anesth Analg. 2016, 122:373-80. 10.1213/ANE.0000000000001048

15. Tavazzi G, Pellegrini C, Maurelli M, et al.: Myocardial localization of coronavirus in COVID-19 cardiogenic shock. Eur J Heart Fail. 2020, 22:911-915. 10.1002/ejhf.1828

16. Peiris JS, Lai ST, Poon LL, et al.: Coronavirus as a possible cause of severe acute respiratory syndrome . Lancet. 2003, 361:1319-1325. 10.1016/s0140-6736(03)13077-2

17. Wang W, Xu Y, Gao R, Lu R, Han K, Wu G, Tan W: Detection of SARS-CoV-2 in different types of clinical specimens. JAMA. 2020, 11:10. 10.1001/jama.2020.3786 


\section{Cureus}

18. Shakoory B, Carcillo JA, Chatham WW, et al.: Interleukin-1 receptor blockade is associated with reduced mortality in sepsis patients with features of macrophage activation syndrome: reanalysis of a prior phase III trial. Crit Care Med. 2016, 44:275-281. 10.1097/CCM.0000000000001402

19. Chen HS, Wang W, Wu SN, Liu JP: Corticosteroids for viral myocarditis . Cochrane Database Syst Rev. 2013, 2013:CD004471. 10.1002/14651858.CD004471.pub3 